\title{
Head Nurses' Interpersonal Relationship and Its Effect on Work Engagement and Proactive Work Behavior at Assuit University Hospitals
}

\author{
Heba Mostafa Ali ${ }^{1}$ Samah Mohamed Abdallah ${ }^{2}$ \& Nahed Shawkat Abo El-magd ${ }^{3}$. \\ 1.Demonstrator in Nursing Administration Department, Faculty of Nursing, Assuit University, Egypt. \\ 2.Prof of Nursing Administration, Faculty of Nursing, Assiut University, Egypt. \\ 3.Assist. Prof of Nursing Administration, Faculty of Nursing, Assiut University, Egypt.
}

\begin{abstract}
Introduction: Hospitals are challenged to achieve highly patient outcomes while facing mounting financial constraints. Studies of high-performing organizations suggest that one key to success is an engaged workforce that acts proactively to resolve performance problems. Aim: Explore head nurses' interpersonal relationships and it's effect on work engagement and proactive work behavior. Study design: A descriptive correlational. Setting: This study was conducted in all departments at Assuit University Hospitals includes (Main Hospital, Pediatric Hospital, Women's Health Hospital). Subject and Method: The study subject consisted of (88) head nurse working in all departments of selected Hospitals. The data collected through self - administered questionnaire which includes personal characteristics data, Relational Coordination, Utrecht Work Engagement and Proactive Work Behavior Scale. Results: There was statistically significant relation between interpersonal relationships among head nurses, nurse administrators \& physicians with work engagement and proactive work behavior. There was statistically significant relation between work engagement and proactive work behavior. Conclusion: There was a positive correlation between interpersonal relationships with work engagement and proactive work behavior. Recommendations: Implement continuous training programs for the different categories of health care providers to improve interpersonal relationships and work engagement \&proactive work behavior.
\end{abstract}

\section{Keywords: Interpersonal Relationships, Work Engagement \& Proactive Work Behavior.}

\section{Introduction}

Interpersonal relationships at work constitute the day to day interaction among co-workers, managers and employees. These relations are a natural part of the work environment and are usually pleasant and creative, but sometimes a source of tension and frustration Schabracq et al., (2003). Interpersonal relationships were defined as the relationship developed over time and based on shared goals, shared knowledge, mutual respect, and quality communication. (Gittell, 2008).

For any organizations, positive relationships between colleagues have benefited. They may attract employees in the first place Tews et al., (2012), can support employees to act more supportively and collegially and improve satisfaction, commitment, and reducing intentions to leave (Morrison, 2004 \& Morrison, 2009).

Engagement at work has emerged as a potentially important employee performance and organizational management topic. Relationship between engagement of the employee at work and organizational outcomes, including those which are performance based \& for most organizations, their existence depend on their ability to satisfy customer needs, while achieving quality, flexibility, innovation and organizational responsibility through the engagement and commitment of employees (Laschinger\& Finegan, 2005).

Schaufeli\& Bakker, (2010) defined work engagement as a general, persistent, affectivecognitive state that is not focused on any particular object, event, individual or behavior characterized by vigor, dedication, and absorption.

In the fact that today's health care organizations expect their health care professional to show initiative, to be proactive, to take responsibility for their own development of achievement behaviors at work, as well as to perform at high levels (Menguc et al., 2012).

Macey\& Schneider, (2008) noted that there are several personality characteristics that will predispose employees to feel engaged. These include extraversion, conscientiousness, trait positive affectivity and proactivity.

Proactive work behavior defined as self-initiated, anticipatory action that aims to change and improve the situation of oneself or environment" and consists of taking charge, voice, initiating innovation and problem prevention (Parker\& Collins, 2010).

\section{Significance of the study}

Much has appeared in professional articles and journals regarding the importance of Interpersonal 
relationship and communication at work. The research that conduct by Warshawsky et al., (2012) found that interpersonal relationships with health teams was most predictive of nurse managers' work engagement and proactive work behavior and from observation in some departments at Assuit University Hospitals, the researcher was observed that the interpersonal relationships and communication between work group are varied, sometimes difficult and may has an impact on work engagement and proactive work behavior of the health team group and there is no nationally research in this point. That is why there is an interest to conduct such type of study to find what the influence of head nurses' interpersonal relationships between head nurses, between head nurses and nurse administrators, and between head nurses and physicians on their work engagement and proactive work behavior.

\section{Aim of the study}

The present study aimed to

Explore head nurses' interpersonal relationships and it's effect on work engagement and proactive work behavior.

Research questions

The following research questions are formulated:

Q1: What is the correlation between head nurses' interpersonal relationships with both other head nurses and nurse administrators and head nurses' work engagement?

Q2: What is the correlation between head nurses' interpersonal relationships with physicians and head nurses' proactive work behavior?

Q3: What is the correlation between head nurses' work engagement and head nurses' proactive work behavior?

\section{Subjects \& Method \\ Technical design}

Involves research design, setting, subject, and data collection tools.

\section{Study design}

The present study was carried out using descriptive correlational research design.

\section{Study setting}

The present study was conducted in all departments at three hospitals of Assuit University Hospitals namely; (Main hospital, Pediatric hospital, and Women's health hospital).

\section{Study subject}

The study subject comprised all head nurses working in departments of Assuit University Hospitals (Main hospital No $=51$ head nurses, Pediatric hospital No $=18$ head nurses, Women's health hospital No $=19$ head nurses), Total No $=88$ head nurses).

\section{Data collection tools}

The data needed for the study was collected using self-administrated questionnaire, it comprised four tools

- Personal characteristics data:It was designed to collect personal data about head nurses include; Hospital name, age, educational qualification, marital status, and years of experience.

- Relational Coordination Scale (RCS): it was developed by Gittell, (2009) and used to measure participants' interpersonal relationships and communication across functional work groups relative to a specific work processes. It consists of 7-items classified to; (3 items) measured the quality of relationship between work groups: (shared knowledge, shared goals, and mutual respect) and (4 items) measured the quality of communication based on (frequency, timeliness, accuracy, and problem solving).

\section{Scoring System}

The responding scoring system was measured by3point Likert scale. Ranging from (0) for never, (1) for often, (3) for always. Each head nurse rated items 3 times to assess the quality of interpersonal relationships with other head nurses, between head nurses and nurse administrators, and between head nurses and physicians.

Utrecht Work Engagement Scale (UWES): it was developed by Schaufeli \& Bakker, (2004) and used to assess head nurses ' work engagement. It consists of 17 items divided into 3 subscale include: vigor (6 items), dedication (5 items) and absorption (6 items).

\section{Scoring System}

The responding scoring system was measured by 3point Likert scale. Ranging from (0) for never, (1) for a few times a month, (2) for every day according to how often the participant experienced the feeling described.

Proactive Work Behavior Scale (PWBS): it was developed by Parker \& Collins, (2010) and used to assess head nurses' proactive work behavior. it consists of 13-items divided into 4 subscale include : problem prevention (3 items) , individual innovation (3 items), voice (4 items) and taking charge (3 items).

\section{Scoring System}

The responding scoring system was measured by 3 point Likert scale. Ranging from (0) for very infrequent, (1) for somewhat frequently, (2) for very frequently.

Administrative design

Official approval to carry out this study was obtained from Directors of Assiut University Hospitals, Nursing Directors of Assiut University Hospitals, and Dean of Faculty of Nursing. 


\section{Operational design}

Preparatory phase

- This phase took about three months from March to May 2016 to finish the proposal of the study.

- After reviewing the available literatures concerning the topic of the study, Arabic translation of the study tools was done.

- And the tools were checked by (7) experts (5) from Nursing Administration Department and (2) from Community Health Nursing Department for validation and reliability was checked through a pilot study, no modification was done.

\section{Ethical considerations}

Study proposal take approved from Ethical Committee in the Faculty of Nursing, Oral agreement was taken from the participants. Confidentiality of obtained data was assured, and the purpose, nature, and the aim of the study was explained to all participants before starting data collection.

\section{Pilot study}

A pilot study was carried out to assess tool clarity, accessibility of the study tools. It has also served in estimating the time needed for filling the forms and to identify problems that may be encountered during the actual data collection. It applied on (10\%) from total sample (10) head nurses from different units of the hospitals and conducted in a week from 1-7/6/ 2016. Data collected from the pilot study was analyzed and no changes were done for the study tools, so the head nurses included in the pilot study was excluded from the total head nurses included in the study.

The study tools were tested for its reliability by using Crombach's Alpha Co- efficient test, it was efficient and test, was $(\boldsymbol{\alpha}=\mathbf{0 . 8 1 5})$ for Relational Coordination Scale (RCS), $(\boldsymbol{\alpha}=\mathbf{0 . 8 2 1})$ for Utrecht Work Engagement Scale (UWES), and it was

$(\boldsymbol{\alpha}=\mathbf{0 . 8 1 3})$ for Proactive Work Behavior Scale (PWBS).

\section{Data collection}

The researcher met with each head nurse in the study to explain the purpose of the study and to ask for participation. After obtaining verbal consent, the study tool was given to the participated head nurses to be filled through self- administered questionnaire. Each participant took about thirteen minutes to fulfill the questionnaire. The whole duration for data collection took about three months from June to August 2016.

\section{Statistical design}

Data entry and statistical analysis were done using SPSS 16.0 Statistical Soft Ware Package. Data were presented using descriptive statistics in the form of frequencies, percentages, mean, standard deviation, range, and chi-square. Pearson correlation analysis was used for assessment of the interrelations among quantitative variables (interpersonal relationships, work engagement \& proactive work behavior). Statistical significance was considered at P-value $\leq$ 0.05 .

\section{Vol , (6) No , (13) April 2018}


Results

Table (1): Personal characteristics of the studied head nurses at Assuit University Hospitals (n=78).

\begin{tabular}{|l|c|c|}
\hline \multicolumn{1}{|c|}{ Items } & \multicolumn{2}{|c|}{ No. $(\mathbf{n}=\mathbf{7 8})$} \\
\hline Hospital: & 47 & $\mathbf{6 0 . 3}$ \\
\hline Main Assiut University Hospital & 15 & 19.2 \\
\hline Pediatric Assiut University Hospital & 16 & 20.5 \\
\hline Woman Assiut University Hospital & 10 & 12.8 \\
\hline Age: (years) & 23 & 29.5 \\
\hline <30 years & 30 & $\mathbf{3 8 . 5}$ \\
\hline $30-<35$ years & 15 & 19.2 \\
\hline $35-<40$ years & $35.64 \pm 5.75(24.0-50.0)$ \\
\hline$\geq 40$ years & \multicolumn{2}{|c|}{} \\
\hline Mean \pm SD (Range) & 65 & $\mathbf{8 3 . 3}$ \\
\hline Qualifications: & 3 & 3.8 \\
\hline Bachelor degree in nursing science & 10 & 12.8 \\
\hline Nursing diploma & \multicolumn{2}{|c|}{} \\
\hline Master degree & 63 & $\mathbf{8 0 . 8}$ \\
\hline Marital status: & 12 & 15.4 \\
\hline Married & 2 & 2.6 \\
\hline Single & 1 & 1.3 \\
\hline Divorced & \multicolumn{2}{|c|}{} \\
\hline Widow & 10 & 12.8 \\
\hline Years of experience: & 46 & $\mathbf{5 9 . 0}$ \\
\hline <10 years & 22 & 28.2 \\
\hline 10 - 15 years & \multicolumn{2}{|c|}{$13.58 \pm 5.28(1.0-26.0)$} \\
\hline$>15$ years & \multicolumn{2}{|c|}{} \\
\hline Mean \pm SD (Range) &
\end{tabular}

Table (2): Mean score of head nurses' interpersonal relationships among other head nurses, nurse administrators and physicians at Assuit University Hospitals (n=78).

\begin{tabular}{|l|c|c|c|c|c|c|}
\hline & \multicolumn{3}{|c|}{ Interpersonal relationships with } & \multirow{2}{*}{ P-value $^{\mathbf{1}}$} & \multirow{2}{*}{ P-value $^{\mathbf{2}}$} & \multirow{2}{*}{ P-value $^{\mathbf{3}}$} \\
\cline { 2 - 4 } & Other head nurses & Nurse administrator & Physicians & & \\
\hline Mean \pm SD & $\mathbf{1 0 . 3 7} \pm \mathbf{3 . 1 5}$ & $8.68 \pm 3.00$ & $8.15 \pm 3.67$ & \multirow{2}{*}{$\mathbf{0 . 0 0 0}^{*}$} & \multirow{2}{*}{$\mathbf{0 . 0 0 0} *$} & \multirow{2}{*}{0.333} \\
\hline Range & $2.0-14.0$ & $0.0-14.0$ & $0.0-14.0$ & & \\
\hline
\end{tabular}

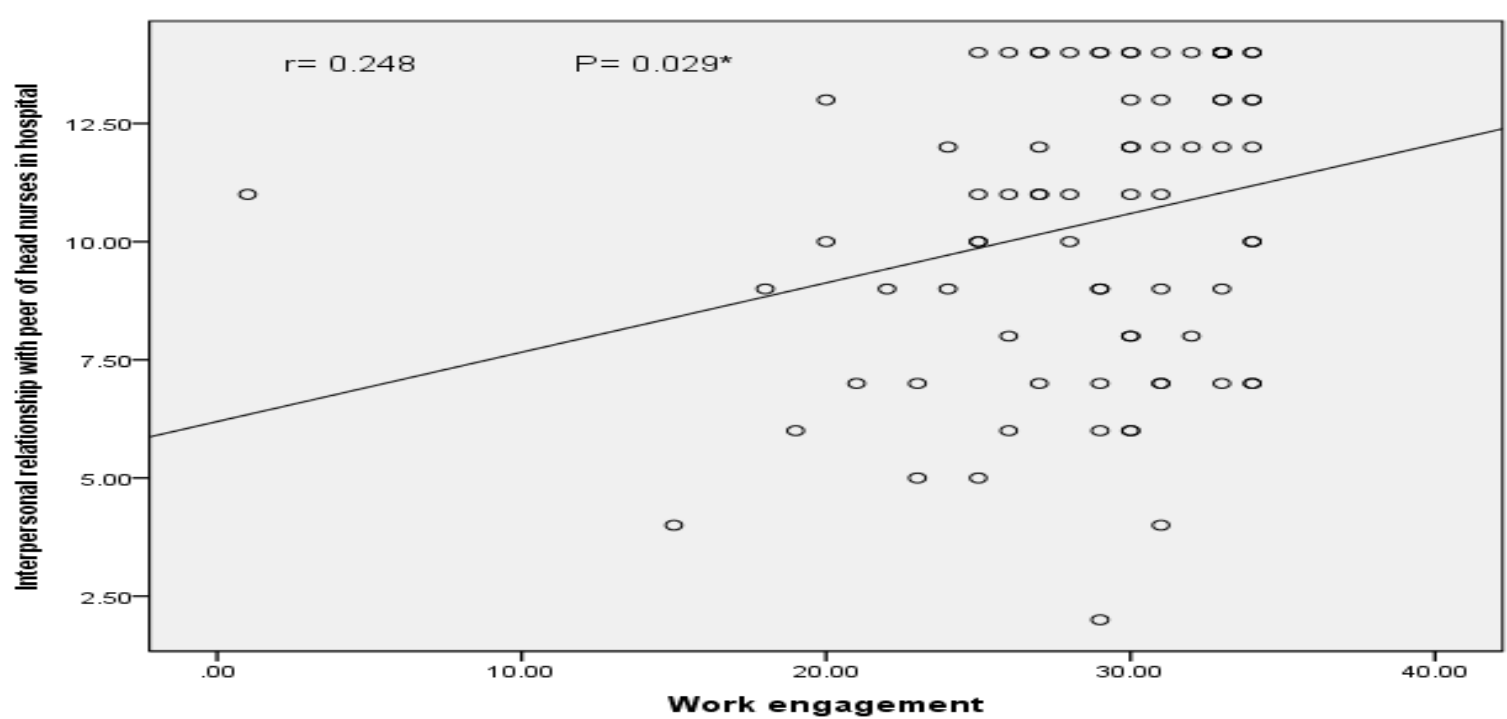

Figure (1): Correlation between interpersonal relationships with other head nurses and work engagement items as reported by the studied head nurses at Assuit University Hospitals $(\mathbf{n}=\mathbf{7 8})$ 


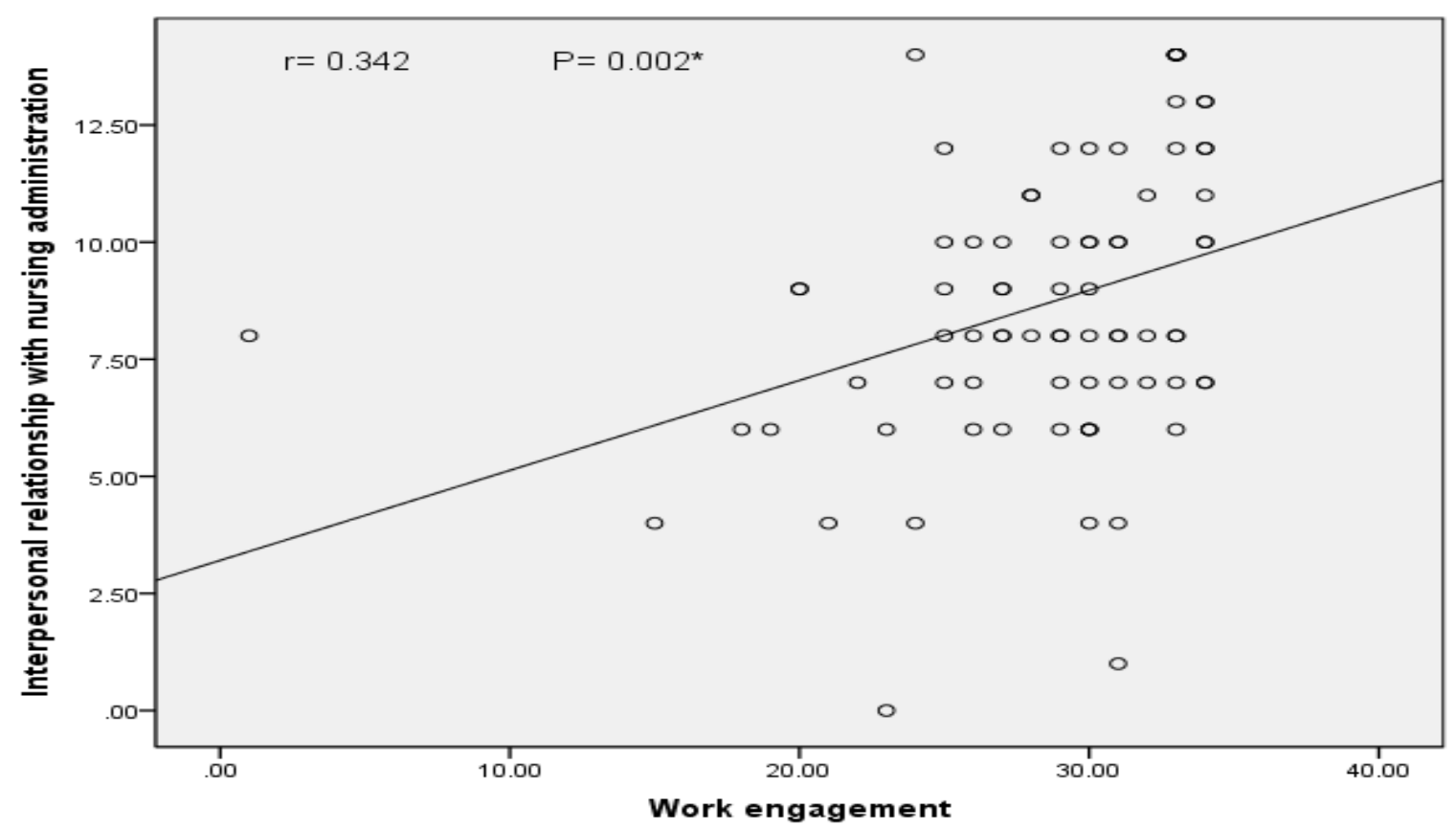

Figure (2): Correlation between interpersonal relationships with nurse administrators and work engagement items as reported by the studied head nurses at Assuit University Hospitals (n=78)

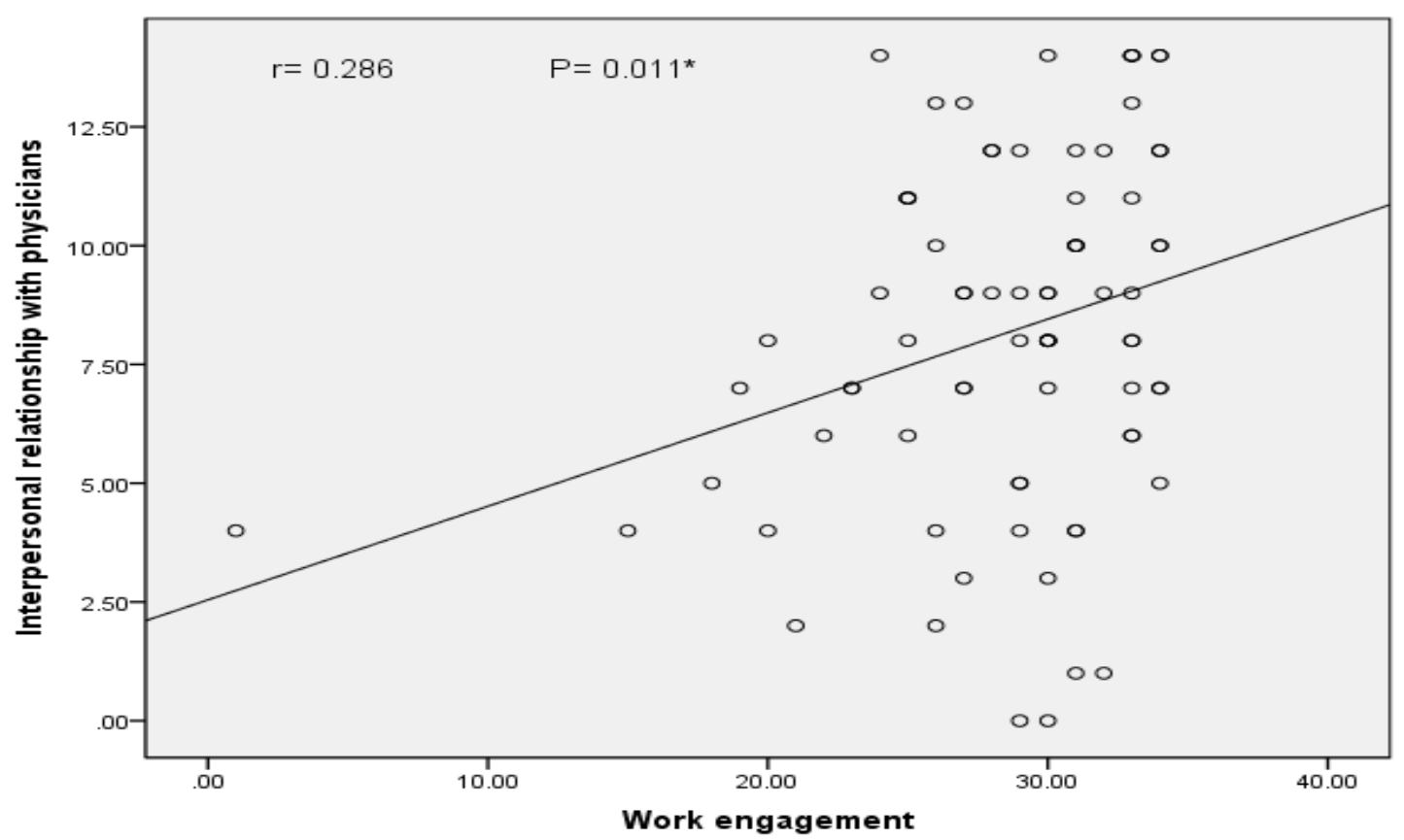

Figure (3): Correlation between interpersonal relationships with physicians and work engagement items as reported by the studied head nurses at Assuit University Hospitals (n=78) 


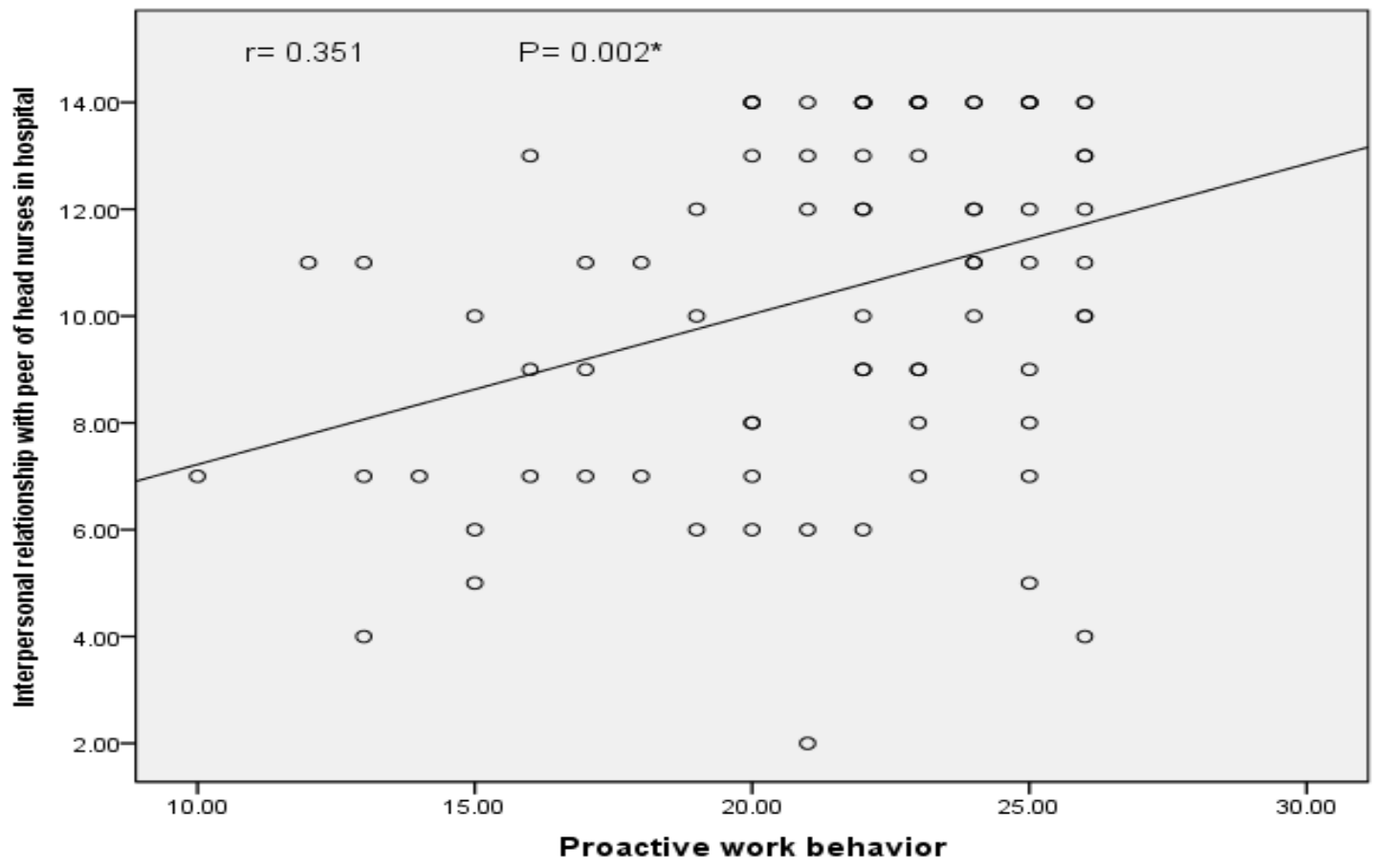

Figure (4): Correlation between interpersonal relationships with other head nurses and proactive work behavior items as reported by the studied head nurses at University Hospitals (n=78)

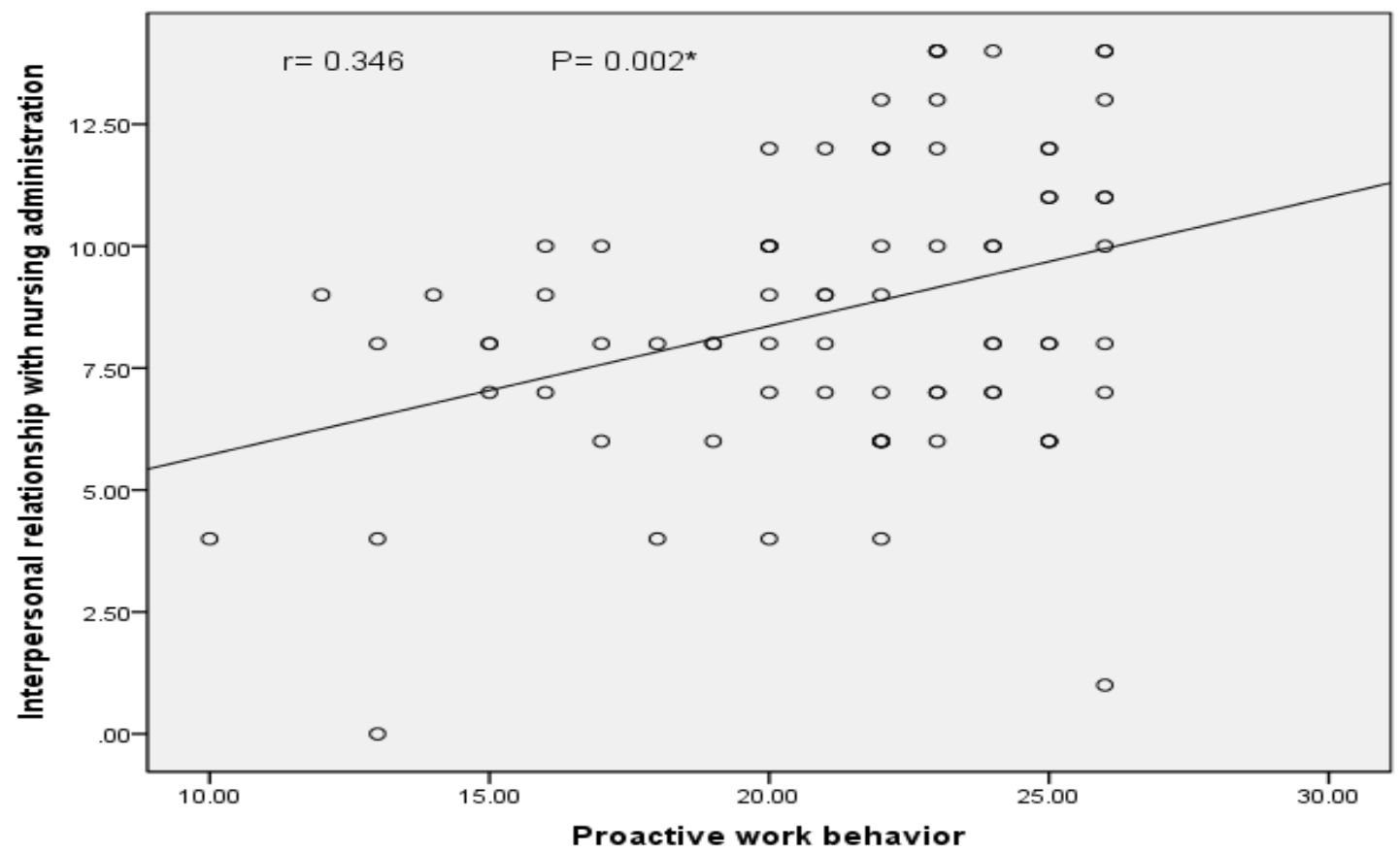

Figure (5); Correlation between interpersonal relationships with nurse administrators and proactive work behavior items as reported by the studied head nurses at University Hospitals $(n=78)$. 


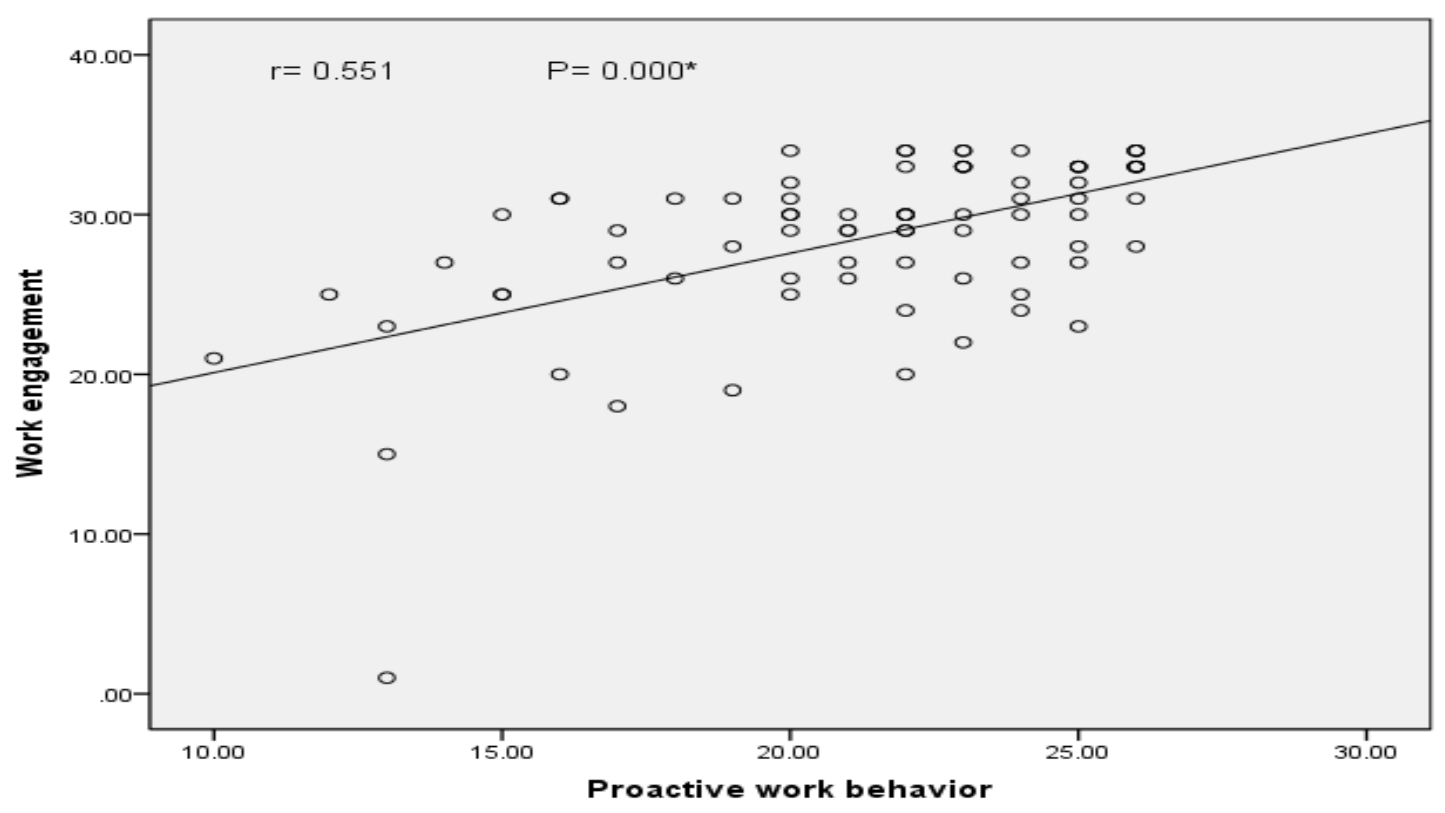

Figure (6): Correlation between work engagement and proactive work behavior items as reported by the studied head nurses at University Hospitals $(n=78)$.

Table (1): Illustrated that, the majority of head nurses having a Bachelor degree in nursing science, married

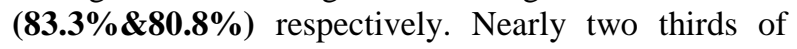
them working at the Main Assiut University Hospital $\mathbf{6 0 . 3 \% ) , ~ m o r e ~ t h a n ~ h a l f ~ o f ~ t h e m ~ h a v e ~ y e a r s ~ o f ~}$ experience between 10 - 15 years $\mathbf{( 5 9 . 0 \% )}$ and more than a third of them aged between $35-<40$ years (38.5\%).

Table (2): Illustrates that, the highest mean score regard to interpersonal relationships was relationship with other head nurses $(\mathbf{1 0 . 3 7} \pm \mathbf{3 . 1 5})$. There was highly statistical significance difference with other head nurses\& nurse administrators $(\mathbf{0 . 0 0 0} \quad \boldsymbol{\& 0 . 0 0 0})$ while there no statistical significance difference with physicians as reported by head nurses.

Figure (1, 2 \&3): Shows that, there was significant positive correlation among interpersonal relationships with other head nurses, nurse administrators \& physicians and work engagement.

Figure (4\&5): Reveals that, there was positive correlation among interpersonal relationships with other head nurses, nurse administrators \& physicians and proactive work behavior. There was highly statistical significance difference between interpersonal relationships with other head nurses \& nurse administrators and proactive work behavior $(\mathbf{0 . 0 0 2} * \mathbf{\& 0 . 0 0 2} *)$. But there was no statistical significance difference between interpersonal relationships with physicians and proactive work behavior.

Figure (6): Reveals that, there was a significant positive correlation between work engagement \& proactive work behavior items $(\mathbf{r}$-value $=\mathbf{0 . 5 5 1}) \&(\mathbf{p}$ value $=0.000 *$ ).

\section{Discussion}

As revealed from the current study, the highest mean score regard to interpersonal relationships was relationships among head nurses each other and there was highly statistical significance difference with head nurses and nurse administrators (table, 2). This might be attributed to frequent contact and interaction between head nurses each other, they become more aware and oriented about each other and their personal and work problems (problems with scheduling, staffing, work condition, etc..) and good and positive relationships between head nurses each other will be developed and be comfortable to communicate these problems to nurse administrators.

This finding was consistent with Upenieks et al., (2009) who mentioned that verbal communication is a primary way of exchanging critical information concerning patient issues in hospital settings. Improving the exchange of information between healthcare providers has been cited as a key component to preventing medical errors and promoting a safe patient environment.

The study findings showed that, there was significant positive correlation among interpersonal relationships with other head nurses, nurse administrators \& physicians and Work engagement (figure 1, 2\& 3) This might be attributed to that when relationship between health care provider was good \&pleasant, all 
of them will like their jobs and be more engaged in it and also encourage others to be more engaged.

This finding was consistent with Carmeli et al., (2009) who mentioned that workplace relationships directly contribute to the level of energy that individuals experience at work. In particular, workplace vigor has shown that positive work relationships provide a contextual backdrop against which vigor flourishes which comprising energy and vitality, experienced at work \& found that individuals who reported high levels of bonding social capital experienced greater energy and vitality on the job which in turn led to enhanced job performance. Also was consistent with Barbieri et al., (2014) who mentioned that high levels of social support are associated with high levels of work engagement, Specifically, results show that people receiving autonomy support from supervisors develop a greater sense of belongingness, become more inspired in their work, and more engrossed in their working tasks.

On the other hand, this findings was inconsistent with Schaufeli et al., (2008) who reported that there are positive associations between coworker support and the vigor and dedication subscales of the Utrecht Work Engagement Scale but not the absorption subscale\& none of the associations between supervisory support and the dimensions of the UWES were significant. Also was inconsistent with Montgomery et al., (2003) who explored the relationships between social support from colleagues, supervisors, and friends on the vigor and dedication dimensions of the UWES and mentioned that of these three sources of social support, only social support from colleagues was positively associated with dedication.

The study findings revealed that, there was positive correlation among interpersonal relationships with other head nurses, nurse administrators \& physicians and proactive work behavior. There was highly statistical significance difference between interpersonal relationships with other head nurses \& nurse administrators and proactive work behavior. But there was no statistical significance difference between interpersonal relationships with physicians and proactive work behavior (figure $4 \&$ 5) This might be attributed to that when relationship between health care providers was good \&pleasant and based on respect each other and complete each other in their role, all of them will like their jobs and be more engaged in it and also encourage other to be more engaged.

This findings was consistent with Gittell, (2002) who mentioned that where employees share common goals, proactive ideas can likely be planned and enacted with greater confidence and greater potential for success \& also the study results was consistent with Bakker \&Demerouti, (2007, 2008) who found that according to the model of work engagement, interpersonal relationships should directly and indirectly, through work engagement, influence proactive work behavior. The study findings showed that, there was significant positive correlation between work engagement \& proactive work behavior items (figure 6). This might be attributed to when head nurses more engaged in their work and know everything about patients and unit, they involuntary thought how to improve unit.

This finding was consistent with Grant et al., (2011) who mentioned that proactive behaviors require energy and effort and the belief that one has the physical, emotional, and cognitive resources to invest in such behaviors is likely to affect the decision to be proactive. Also the study results was consistent with Salanova\& Schaufeli, (2008), Warshawsky et al., (2012) who mentioned that work engagement has also been found to be positively and significantly related to personal initiative and proactive work behavior \& found that work engagement mediates the relationship between job resources (i.e., job control, feedback, variety) and proactive behavior.

\section{Conclusion}

In the light of the study results, the following conclusions can be drawn:

- There was highly statistically significant difference between head nurses and between head nurses\& nurse administrators regarding to interpersonal relationships, while there was no statistically significant difference between head nurses\& physicians.

- There were significant positive correlations between interpersonal relationships with other head nurses, nurse administrators and physicians with work engagement and proactive work behavior.

- There was no statistically significant difference between interpersonal relationships with physicians and proactive work behavior.

- There was a significant positive correlation between work engagement \& proactive work behavior.

\section{Recommendations}

In the light of the results of this study the following recommendations will be suggested:

- Create an environment of respect and acceptance that help nurse administrators, head nurses and nursing staff to develop and achieve their goals.

- Promote head nurses' work engagement, through reward of good performance, which help nurses to gain more positive experiences about their work.

- Promote head nurses ' proactive work behavior throughout identifying the possible problems, finding new solutions and innovative approaches to deal with it, and providing active leadership role. 
- Implement continuous training programs for the different categories of health care providers to improve interpersonal relationships, work engagement \&proactive work behavior.

\section{References}

1- Bakker A., \& Demerouti E., (2008): Towards A Model of Work Engagement, Career Development International, Vol .13, No.3, P. p (209-223). Doi:10.1108/13620430810870476.

2- Bakker A., \& Demerouti E., (2007): The Job Demands-Resources Model: State of the Art. Journal of Managerial Psychology, Vol .22, No.3, P.p (309-328). Doi:10.1108/02683940710733115.

3- Barbieri B., Amato C., Passafaro P., Dal Corso L., \& Picciau M., (2014): Social Support, Work Engagement, and Non-Vocational Outcomes in People With Severe Mental Illness, Tpm Vol. 21, No. 2, P. p (181-196 ) Doi:10.4473/Tpm21.2.5 - (C) Cise.

4- Carmeli A., Ben-Hador B., Waldman D., \& Rupp D., (2009): How Leaders cultivate Social Capital and Nurture Employee Vigor: Implications for Job Performance, Journal of Applied Psychology, Vol. 94, No.6, P.p (1553-1561). Doi: 10.1037/A0016429.

5- Gittell J., (2002): Coordinating Mechanisms In Care Provide Groups: Relational Coordination as a Mediator and Input Uncertainty As A Moderator of Performance Effects, Management Science, Vol . 48, No. 11, P. p (1408-1426). Doi: 10.1287/Mnsc.48.11.1408.268.

6- Gittell J., (2008): Relationships and Resilience: Care Providers Responses to Pressures from Managed Care. Journal of Applied Behavioral Science, Vol . 44, No .1, P. p (25-47).

7- Doi: 10.1177/0021886307311469.

8- Gittell J., (2009): High Performance Healthcare: Using the Power of Relationships to Achieve Quality, Efficiency, and Resilience. By J. H, Chapter 3,1 ${ }^{\text {st }}$ Ed , Copyright (2009) By McgrawHill. Reprinted With Permission: New York, P. p (18- 19)

9- Grant. A., Nurmohamed S., Ashford S., \& Dekas K., (2011): The Performance Implications of Ambivalent Initiative: The Interplay of Autonomous and Controlled Motivations, Organizational Behavior and Human Decision Processes, Vol.116, No.2, P.p (241-251).

10- Doi: 10.1016/J.Obhdp.2011.03.004.

11- Laschinger H., \& Finegan J., (2005): Empowering Nurses for Engagement And Health In Hospital Settings. Journal of Nursing Administration, Vol .35 , No. 10, P.p (439-449).

12- Macey W., \& Schneider B., (2008): 'The Meaning of Employee Engagement', Industrial And
Organizational Psychology: Perspectives on Science And Practice, $1^{\text {st }}$ Ed, P. p (3-30).

13- Menguc B., Auh. S., Fisher M., \& Haddad A., (2012): To Be Engaged or Not to Be Engaged: The Antecedents and consequences of Service Employee Engagement, Doi:10.1016/J.Jbusres.2012.01.007.

14- Montgomery A., Peeters. M., Schaufeli W., \& Den Ouden M., (2003): Work-Home Interference Among Newspaper Managers: Its Relationship With Burnout And Engagement. Anxiety, Stress, and Coping, 16, P. p (195-211). Doi:10.1080/1061580021000030535.

15- Morrison R., (2004): Informal relationships in the workplace: Associations with job satisfaction, organizational commitment and turnover intentions, New Zealand Journal of Psychology, Vol.33, No. 3, P. p (114-128).

16- Morrison R., (2009): Organizational outcomes of friendships: in R. L. Morrison \& S. Wright Friends and Enemies in Organizations: A Work Psychology Perspective. London: Palgrave Macmillan, $2^{\text {nd }}$ Ed, P.p (22-24).

17- Parker S., \& Collins C., (2010): Taking Stock: Integrating and Differentiating Multiple Proactive Behaviors. Journal of Management, Vol. 36, No. 3, P.p (633-662). Doi:10.1177/0149206308321554

18- Salanovaa M.,\& Schaufelib W., (2008): CrossNational Study of Work Engagement as A Mediator between Job Resources and Proactive Behavior, The International Journal of Human Resource Management, Vol. 19, No. 1, P. p (116-131). Doi:10.1080/09585190701763982.

19- Schabracq M., Winnubst G., \& Cooper C., (2003): Conflict at Work and Individual Well-being in The Handbook of Work \& Health Psychology, second edition, Jon Wiley \&Sons Ltd, West Sussex, England, P. p (495-515) .

20- Schaufeli W., Taris T., \& Van Rhenen. W., (2008): Workaholism, Burnout, and Work Engagement: Three of A Kind or Three Different Kinds of Employee Well-Being? Applied Psychology, Vol. 57, No. 2, P. p (173-203).

21- Schaufeli W., \& Bakker A., (2004): Job Demands, Job Resources, and Their Relationship with Burnout and Engagement: A Multi sample Study. Journal of Organizational Behavior, Vol .25, No. 3, P. p (293-315). Doi:10.1002/Job.248.

22- Schaufeli W., \& Bakker A., (2010): Defining And Measuring Work Engagement: Bringing Clarity to The Concept, Work Engagement: A Handbook of Essential Theory And Research, 2nd Ed, New York City, Ny, (P.P. 10-24).

23- Tews M., Michel J., \& Bartlett A., (2012): The fundamental role of workplace fun in applicant attraction, Journal of Leadership \& Organizational 
Studies, Vol. 19, No. 1, P.p (105-114). Doi: 10.1177/1548051811431828

24- Upenieks V., Lee. E., Flanagan N., \& Doebbling B., (2009): Healthcare Team Vitality Instrument (Htvi): Developing a Tool Assessing Healthcare Team Functioning. Journal of Advanced Nursing, Vol .66, No .1, P. p (168-176).

25- Warshawsky N., Havens D., \&Knafl G., (2012): The Influence of Interpersonal relationships on Nurse Managers' Work Engagement and Proactive work Behavior, The Journal of Nursing Administration, Vol. 42, No. 9, P. p (418-425). Doi:10.1097/Nna.0b013e3182668129. 